Modern Physics Letters A, Vol. 11, No. 29 (1996) 2407

(C) World Scientific Publishing Company

\title{
ERRATA
}

\section{IS LEPTON-QUARK MASS PRESET BY A CHARGE-NUMBER RELATION?}

\author{
[Mod. Phys. Lett. A, Vol. 11, No. 20 (1996) 1687-1689]
}

Gerald Rosen

On p. 1688, the numerical prefactor that precedes the quantity $\left(|Q|-Q^{2}\right)$ below Eq. (3) was inverted in typesetting; the associated equation should read

$|B|=\frac{3}{2}\left(|Q|-Q^{2}\right)$, which yields $|B|=0$ for $|Q|=0,1$ and $|B|=\frac{1}{3}$ for $|Q|=\frac{1}{3}, \frac{2}{3}$. 